\title{
Removal of heavy oil from contaminated surfaces with a detergent formulation containing biosurfactants produced by Pseudomonas spp.
}

\author{
Charles Bronzo B Farias ${ }^{1,2}$, Rita de Cássia F Soares da Silva ${ }^{1,3}$, Fabíola Carolina G Almeida ${ }^{1}$, Valdemir A Santos ${ }^{1,2}$ \\ ${ }^{3}$, Leonie A Sarubbo ${ }^{\text {Corresp. 1, 2, } 3}$ \\ 1 Instituto Avançado de Tecnologia e Inovação, RECIFE, PE, Brasil \\ 2 Renorbio, Universidade Federal Rural de Pernambuco, RECIFE, PE, Brasil \\ 3 Escola Icam Tech, Universidade Católica de Pernambuco, RECIFE, PE, Brasil \\ Corresponding Author: Leonie A Sarubbo \\ Email address: leonie.sarubbo@unicap.br
}

Industrial plants powered by heavy oil routinely experience problems with leaks in different parts of the system, such as during oil transport, the lubrication of equipment and mechanical failures. The surfactants, degreasing agents and solvents that make up detergents commonly used for cleaning grease-covered surfaces are synthetic, nonbiodegradable and toxic, posing risks to the environment as well as the health of workers involved in the cleaning process. To address this problem, surfactant agents of a biodegradable nature and low toxicity, such as microbial surfactants, have been widely studied as an attractive, efficient solution to replace chemical surfactants in decontamination processes. In this work, the bacterial strains Pseudomonas cepacia CCT 6659, Pseudomonas aeruginosa UCP 0992, Pseudomonas aeruginosa ATCC 9027 and Pseudomonas aeruginosa ATCC 10145 were evaluated as biosurfactant producers in media containing different combinations and types of substrates and under different culture conditions. The biosurfactant produced by $P$. aeruginosa ATCC 10145 cultivated in a mineral medium composed of $5.0 \%$ glycerol and $2.0 \%$ glucose for $96 \mathrm{~h}$ was selected to formulate a biodetergent capable of removing heavy oil. The biosurfactant was able to reduce the surface tension of the medium to $26.40 \mathrm{mN} / \mathrm{m}$, with a yield of approximately $12.00 \mathrm{~g} / \mathrm{L}$ and a critical micelle concentration of $60.00 \mathrm{mg} / \mathrm{L}$. The biosurfactant emulsified $97.40 \%$ and dispersed $98.00 \%$ of the motor oil. The detergent formulated with the biosurfactant also exhibited low toxicity in tests involving the microcrustacean Artemia salina and seeds of the vegetable Brassica oleracea. The detergent was compared to commercial formulations and removed $100 \%$ of the Special B1 Fuel Oil (OCB1) from different contaminated surfaces, demonstrating potential as a novel green remover with industrial applications. 
1 Removal of heavy oil from contaminated surfaces

2 with a detergent formulation containing biosurfactants

3 produced by Pseudomonas spp.

4

5

6

7

8

9

10

11

12

13

14

15

16

17

18

19

20

21

22

23

24

25

26

27

28

29

30

31

32

33

34

35

36

37

38

39

40

41

42

43

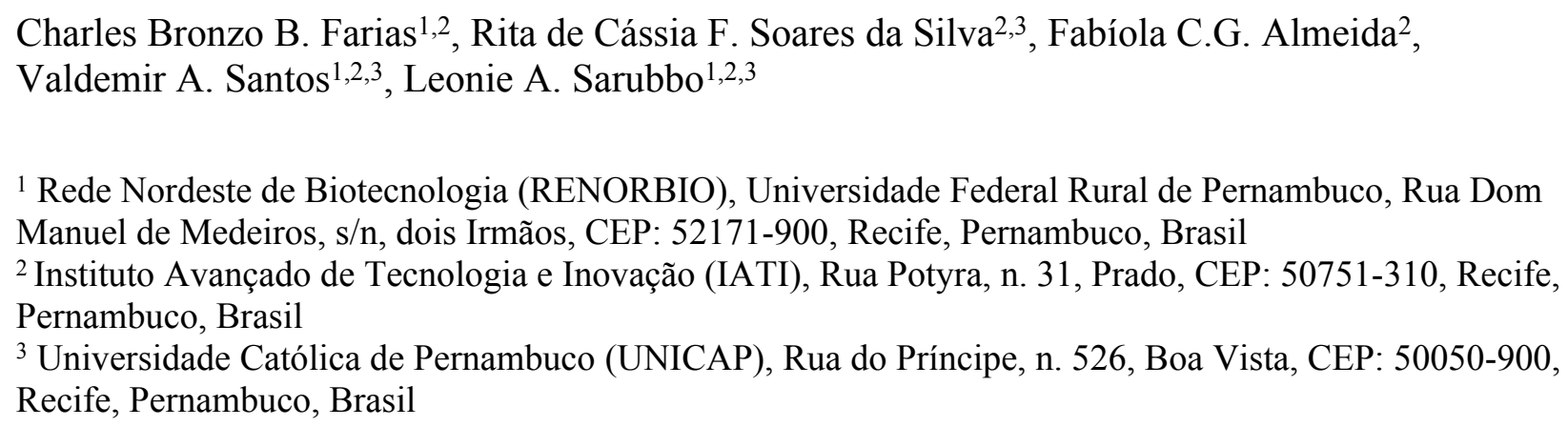

\section{Abstract}

Industrial plants powered by heavy oil routinely experience problems with leaks in different parts of the system, such as during oil transport, the lubrication of equipment and mechanical failures. The surfactants, degreasing agents and solvents that make up detergents commonly used for cleaning grease-covered surfaces are synthetic, non-biodegradable and toxic, posing risks to the environment as well as the health of workers involved in the cleaning process. To address this problem, surfactant agents of a biodegradable nature and low toxicity, such as microbial surfactants, have been widely studied as an attractive, efficient solution to replace chemical surfactants in decontamination processes. In this work, the bacterial strains Pseudomonas cepacia CCT 6659, Pseudomonas aeruginosa UCP 0992, Pseudomonas aeruginosa ATCC 9027 and Pseudomonas aeruginosa ATCC 10145 were evaluated as biosurfactant producers in media containing different combinations and types of substrates and under different culture conditions. The biosurfactant produced by $P$. aeruginosa ATCC 10145 cultivated in a mineral medium composed of 5.0\% glycerol and $2.0 \%$ glucose for $96 \mathrm{~h}$ was selected to formulate a biodetergent capable of removing heavy oil. The biosurfactant was able to reduce the surface tension of the medium to $26.40 \mathrm{mN} / \mathrm{m}$, with a yield of approximately $12.00 \mathrm{~g} / \mathrm{L}$ and a critical micelle concentration of $60.00 \mathrm{mg} / \mathrm{L}$. The biosurfactant emulsified $97.40 \%$ and dispersed $98.00 \%$ of the motor oil. The detergent formulated with the biosurfactant also exhibited low toxicity in tests involving the microcrustacean Artemia salina and seeds of the vegetable Brassica oleracea. The detergent was compared to commercial formulations and removed $100 \%$ of the Special B1 Fuel Oil (OCB1) from different contaminated surfaces, demonstrating potential as a novel green remover with industrial applications.

\section{Introduction}


44 Fuel and lubricant spills that occur in industries during the filling machines and storage tanks and 45 the washing of equipment are one of the causes of the accumulation of petroleum byproducts in 46 the environment. For engines contaminated with lubricating oil, the removal of adhered grease poses a different challenge from contamination generated by oily sludge, as the cleaning process requires the direct application of a detergent, surfactant or solvent, often generating further environmental problems due to the toxicity and accumulation of these substances (Rocha e Silva et al., 2019).

Detergents are generally comprised of a mixture of surfactants (nonionic and anionic, constituting 1-50\%) plus volatile organic solvents, stabilizers, and other additives capable of reducing the surface/interfacial tension of water, though exact compositions are proprietary information (Thomas et al., 2021). For instance, the Corexit dispersants are a mixture of hydrocarbons (60-100\%), organic sulfonic acid salts (10-30\%), and propylene glycol (1-5\%) (Rongsayamanont et al., 2017). Solvents are used to reduce the viscosity of surfactants, to dilute the detergent, to lower its freezing point and to optimize its concentration, while stabilizers help adjust $\mathrm{pH}$ and color, stop corrosion, and increase hard water stability of formulations (Dave and Ghaly, 2011).

Detergents are continually released into the environment, as a result of their wide industrial applications, contributing to the pollution of rivers, oceans and soil. Surfactants, which are the main components of detergent formulations, are responsible for foaming in rivers and affect the physicochemical properties of soils, causing harm to the organisms that inhabit these ecosystems due to their prolonged presence in the environment (Drakontis \& Amin, 2020; Farias et al., 2021; Silva \& Sarubbo, 2021).

Most surfactants in commercial detergents and degreasing formulations are synthesized from petroleum. However, environmental legislation has motivated the development of natural surfactants, such as microbial surfactants, as alternatives to existing products. These biosurfactants are produced from renewable sources and are efficient, non-toxic, biodegradable and stable under extreme environmental conditions (Farias et al., 2021; Markande et al., 2021).

Many types of biosurfactants have been produced in recent decades, especially those obtained from bacteria of the genus Pseudomonas, which mainly produce glycolipid biosurfactants composed of a hydrophilic head formed by rhamnose molecules and a hydrophobic tail that contains fatty acids (Bezerra et al., 2018). The production of rhamnolipids by Pseudomonas has the advantages of obtaining a high-quality surfactant within a short culture time. However, further processing often poses a problem in the production of rhamnolipids, especially due to the low yields (Ptaza \& Achal, 2020).

The development of strategies that enable the application of biosurfactants on an industrial scale is of fundamental importance. Such strategies include the selection of adequate substrates, the determination of optimal culture conditions and the improvement of purification processes (Santos et al., 2016). Moreover, depending on the application purpose, the purification step can be eliminated, which substantially reduces the cost of the process. Thus, the oil industry and environmental applications have become greatest markets for these biomolecules, as such applications have minimal purity specifications (Jimoh \& Lin, 2019).

Since the cost of production is still a limitation for establishing biosurfactants on the market, they have been blended with various types of cheaper synthetic surfactants. In general, mixed surfactant systems provide superior properties compared to individual surfactants, such as lower interfacial tension (Shah et al., 2019). For example, the aqueous binary system of the Gemini cationic surfactant, ethanediyl-1,3 bis (dodecyl dimethyl ammonium bromide) 
90

91

92

93

94

95

96

97

98

99

100

101

102

103

104

105

106

107

108

109

110

111

112

113

114

115

116

117

118

119

120

121

122

123

124

125

126

127

128

129

130

131

132

133

134

135

(represented as 12-3-12) and the bacterial surfactant Surfactin was able to reduce the interfacial tension of petroelum (Lin et al., 2016). Jian et al. (2011) described that binary mixtures of synthetic surfactants and plant biosurfactants (saponin) showed more foaming capacity and less interfacial activity than the individual components. Song et al. (2013) showed that a mixture of soporolipids and rhamnolipid with polysorbate- 80 , sorbet- 40 and ethylene glycol butyl was able of dispersing crude oil. Bio-based dispersants have also been formulated by mixing biosurfactants with chemical surfactants, as their synergistic behavior can increase pollutant washing efficiency by increasing the pollutant solubility (Zhu et al., 2020; Baharuddin et al., 2020). A bio-based washing agent prepared by mixing $0.3 \%$ lipopeptides (an anionic biosurfactant from Bacillus subtilis GY19) and 2\% Dehydol LS7TH (a nonionic fatty alcohol ethoxylate oleochemical surfactant) removed $92 \%$ of $15 \%(\mathrm{w} / \mathrm{w})$ petroleum hydrocarbons (Arpornpong et al., 2020).

Although upstream and downstream processes for the production of biosurfactants have been extensively investigated, studies describing the formulation of novel, efficient products containing biosurfactants are still restrict. Therefore, the aim of this work was to investigate the potential application of biosurfactants produced by bacteria of the genus Pseudomonas from previously established substrates and culture conditions in the formulation of a detergent capable of removing heavy oils. The study of a newly formulated washing agent based on the use of microbial surfactants can become the commercial application of these biomolecules more feasible in the near future.

\section{Materials \& Methods}

\section{Microorganisms}

The bacterial strains Pseudomonas cepacia CCT6659 (obtained from the culture bank of the André Tosello Research and Technology Foundation located in the city of Campinas, São Paulo, Brazil) Pseudomonas aeruginosa ATCC 9027, Pseudomonas aeruginosa ATCC 10145 and Pseudomonas aeruginosa UCP 0992 (obtained from the culture bank of the Environmental Science Research Center (NPCIAMB) of the Catholic University of Pernambuco, Brazil) were used as biosurfactant producers. The cultures were maintained in test tubes with solid nutritive agar slants under refrigeration at $4{ }^{\circ} \mathrm{C}$.

\section{Preparation of inoculum}

For bacterial growth, the $\mathrm{CN}$ (nutrient broth) medium was used with the following composition: meat extract $(0.1 \%)$, yeast extract $(0.2 \%)$, peptone $(0.5 \%)$ and sodium chloride $(0.5 \%)$ at $\mathrm{pH} 7.0$. The growth parameters were temperature of $28^{\circ} \mathrm{C}$ and stirring at $150 \mathrm{rpm}$ for 16 hours until obtaining an optical density (OD) of 0.7 (corresponding to an inoculum of $10^{7} \mathrm{CFUs} / \mathrm{mL}$ ) at 600 $\mathrm{nm}$ with a concentration of $2.0 \%(\mathrm{v} / \mathrm{v})$.

\section{Production of biosurfactants}

The culture conditions and production media tested for each microorganism were initially established based on previous experiments carried out at our laboratories. The P. cepacia CCT6659, $P$. aeruginosa UCP 0992, P. aeruginosa ATCC 9027 and $P$. aeruginosa ATCC 10145 strains were then tested for biosurfactant production using the carbon sources and culture conditions described in Table 1.

The biosurfactant from $P$. cepacia CCT6659 was produced in a mineral medium containing $0.05 \% \mathrm{KH}_{2} \mathrm{PO}_{4}, 0.1 \% \mathrm{~K}_{2} \mathrm{HPO}_{4}, 0.05 \% \mathrm{MgSO}_{4} .7 \mathrm{H}_{2} \mathrm{O}, 0.01 \% \mathrm{KCl}, 0.001 \% \mathrm{FeSO}_{4} .7 \mathrm{H}_{2} \mathrm{O}$ and 0 . 
136

137

138

139

140

141

142

143

144

145

146

147

148

149

150

151

152

153

154

155

156

157

158

159

160

161

162

163

164

165

166

167

168

169

170

171

172

173

174

175

176

177

178

179

180

181

$2 \% \mathrm{NaNO}_{3}$ supplemented with carbon and nitrogen sources, as described by Soares da Silva et al. (2017). The biosurfactants from P. aeruginosa UCP 0992, P. aeruginosa ATCC 9027 and $P$. aeruginosa ATCC 10145 were produced in a mineral medium containing $0.1 \% \mathrm{~K}_{2} \mathrm{HPO}_{4}, 0.1 \%$ $\mathrm{K}_{2} \mathrm{HPO}_{4}, 0.02 \% \mathrm{MgSO}_{4} .7 \mathrm{H}_{2} \mathrm{O}, 0.02 \% \mathrm{CaCl}_{2} . \mathrm{H}_{2} \mathrm{O}$ and $0.005 \% \mathrm{FeCl}_{3} .6 \mathrm{H}_{2} \mathrm{O}$ supplemented with the substrates described in Table 1. Medium surface tensions were between $55-57 \mathrm{mN} / \mathrm{m}$ prior to inoculation.

\section{Isolation of biosurfactants}

The most promising media and culture conditions based on the best surface tension values were selected for isolation of the biosurfactants, which were extracted with the addition of ethyl acetate $\left(\mathrm{C}_{4} \mathrm{H}_{8} \mathrm{O}_{2}\right)$ to the broth obtained after fermentation $(1: 1, \mathrm{v} / \mathrm{v})$. The mixture was centrifuged at $5000 \mathrm{rpm}$ for $10 \mathrm{~min}$, stirred vigorously for 15 minutes and allowed to stand until phase separation. The organic phase was removed, and the operation was repeated twice more. The product was concentrated from the combined organic phases, which were evaporated at $40^{\circ} \mathrm{C}$ in a rotary evaporator. A viscous yellowish product was obtained, which was treated with $\mathrm{NaOH}$ and washed with acetone for maximum removal of impurities and dirt. The yield of the isolated biosurfactant was expressed as $\mathrm{g} / \mathrm{L}$.

\section{Determination of surface tension and critical micelle concentration}

Surface tension was measured in an automatic tensiometer (KSV Sigma 700, Finland) using a $\mathrm{Du}$ Noüy ring. For such, the platinum ring was immersed in dilutions of the isolated biosurfactants $(0.1 \mathrm{~g} / \mathrm{L})$ in distilled water and the force required to pull the ring through the airliquid interface was recorded. The critical micelle concentration (CMC) of the previously isolated biosurfactants was determined by measuring the surface tension of a water sample during the gradual addition of the surfactant until reaching a constant tension value. The CMC was expressed as $\mathrm{mg} / \mathrm{L}$ of the isolated surfactants.

\section{Determination of emulsification index}

To determine the emulsification activity of the biosurfactants, samples of cell-free broth (crude biosurfactant) were analyzed based on Cooper \& Goldenberg (1987). For such, $3.0 \mathrm{~mL}$ of a hydrophobic compound (soybean oil, corn oil or motor oil) and $3.0 \mathrm{~mL}$ of the biosurfactant solution were placed in a test tube and the mixture was vortexed for one minute. After 24 hours, the percentage of the emulsion was calculated as follows:

$\mathrm{E}=100 \times \mathrm{EP} / \mathrm{H}(1)$

in which EP is the height of the emulsified phase and $\mathrm{H}$ is the total height of the mixture (both expressed in centimeters). Emulsifying activity prior to inoculation was used as the negative control for each culture medium. All analyses were performed with four experiments.

\section{Dispersion of hydrophobic contaminant}

The ability of the biosurfactants to disperse an oil slick was simulated in the laboratory by contaminating water samples with 5\% motor oil. The crude biosurfactants (cell-free broth) were added at proportions of 1:2, 1:8 and 1:25 (vol/vol) of biosurfactant/oil. Negative controls were carried out with distilled water. The results were observed visually and the relation between the required volume of biosurfactant and dimensions of the formed halo was calculated (Saeki et al., 2009). 


\section{Maximization of selected biosurfactant extraction}

Based on the results of the previous experiments involving the determination of surface tension, the emulsification index and oil dispersion, only one biosurfactant (i.e., that produced by $P$. aeruginosa ATCC 10145 cultured in mineral medium composed of 5.0\% glycerol and $2.0 \%$ glucose for $96 \mathrm{~h}$ ) was selected for the subsequent experiments. Three biosurfactant extraction and isolation processes (described below) were evaluated considering the increase in yield obtained with few downstream steps.

Chloroform/methanol system: For isolation of the biosurfactant, the $\mathrm{pH}$ of the cell-free broth was initially adjusted to 2.0 with a $6 \mathrm{M}$ solution of $\mathrm{HCl}$. The same volume of chloroform/methanol $(2: 1, \mathrm{v} / \mathrm{v})$ was added. The mixture was stirred vigorously for 15 minutes and left to stand for phase separation. The organic phase was removed, and the operation was repeated twice more. The product was concentrated from the collected organic phases using a rotary evaporator (Silva et al., 2020).

Extraction by acid precipitation: A $2 \mathrm{~N} \mathrm{HCl}$ solution was used to acidify the supernatant containing the biosurfactant until reaching $\mathrm{pH} 2$. The mixture was then incubated for 24 hours at $4{ }^{\circ} \mathrm{C}$. The formed precipitate was collected by centrifugation at $10000 \mathrm{rpm}$ and $4{ }^{\circ} \mathrm{C}$ for $30 \mathrm{~min}$. The precipitate was then subjected to a drying process for 24 hours and then separated for subsequent tests (Shah et al., 2016).

Foam fractionation isolation: A simple fractionation system (Figure 1) was used to recover the biosurfactant contained in the foam. In this system, the cell-free broth was fed into the top of the flask with the aid of a peristaltic pump (Winterburn et al., 2011). The foam was collected in another reservoir, forming a concentrated biosurfactant solution after coalescence. Foam fractionation was performed for $1 \mathrm{~h}$ to ensure stable foam production conditions and the sample was collected at the end of the process. Foam fractionation performance was measured in terms of enrichment and biosurfactant recovery standards, which are defined in the following equations:

Enrichment $=\frac{C f}{C i}$

Recovery $=\frac{C f V f}{C i V i} \times 100$

in which $C f$ is the concentration of biosurfactant in the foamate, $C i$ is the coincident biosurfactant concentration in the feeder, $V i$ is the initial liquid volume and $V f$ is the volume of foamate collected. To compare the yield obtained with this method, biosurfactant concentration in the foamate was determined through chloroform/methanol extraction.

\section{Application of biosurfactant in formulation of industrial detergent}

After isolation, the selected biosurfactant was used as the main component of a detergent. To define the most promising formulation, different formulations were initially investigated using natural components. Biodegradable, non-toxic compounds were selected based on previous studies (Rocha e Silva et al., 2020) for the formulation of a detergent capable of removing heavy oil. The formulation consisted of a natural organic solvent to maximize the fluidization of the heavy oil, a thickening fatty alcohol to increase the viscosity of the formula, a gum as an emulsion stabilizer and the microbial biosurfactant for the removal the oily fraction during the surface cleaning process. Previously, the formulation components, i.e., the isolated biosurfactant $(10 \%)$, the natural organic solvent and the thickening fatty alcohol $(10 \%)$, were tested $(30 \mathrm{~mL})$ separately for oil removal to ensure the viability of the formulation containing the biosurfactant, 
227

228

229

230

231

232

233

234

235

236

237

238

239

240

241

242

243

244

245

246

247

248

249

250

251

252

253

254

255

256

257

258

259

260

261

262

263

264

265

266

267

268

269

270

271

as it is described below using the surface of a glass slide of known mass contaminated with 100 $\mu \mathrm{L}$ of heavy oil.

Tests were then conducted to determine the best percentage of each component of the formula. The mixing of all components was performed in a mechanical stirrer (Tecnal LTDA, Brazil) at $2000 \mathrm{rpm}$ for $30 \mathrm{~min}$ at $80^{\circ} \mathrm{C}$. The formation of phases was followed visually over the course of a month. The purpose of quantifying the compounds was to obtain a stable emulsion with the smallest possible amount of each component. All proportions of the compounds are detailed in Table 2. The formulations were prepared by dissolving the solid components and adding the solvent to complete $100 \%$ of the total mixture.

The efficiency of the formulations was determined based on the stability of the emulsions (no phase separation) and the removal of heavy oil impregnated on different surfaces, as described below. The formulation with the smallest amounts of the components, best stability and greatest oil removal was selected for tests on different surfaces. The selected formulation was subjected to comparative tests with four synthetic commercial detergents of industrial use (identified as commercial detergent A, B, C and D) for cleaning parts, floors and machinery impregnated with heavy oil. Detergent $\mathrm{A}$ is formulated with sodium silicates, amines and alcohols (pH 12.0 to 14.0). Detergent B has phosphoric acid and paint strippers (pH 1.0 to 4.0). Detergent $C$ is formulated with ammonium hydroxide and detergent $D$ is a set of hydrogenated (aliphatic and naphthenic) alkaline solvents with high dielectric strength.

\section{Assessment of toxicity of industrial detergent against Artemia salina}

The toxicity test was conducted using microcrustacean (Artemia salina) larvae as the toxicity indicator with test solutions of the industrial detergent diluted at proportions of 1:5 and 1:10 (v/v) prepared in distilled water and used at concentrations of 1 and $2 \%$. Larvae were used within one day of hatching. The tests were conducted in $15-\mathrm{ml}$ penicillin tubes containing 10 shrimp larvae in $10 \mathrm{ml}$ of seawater. The larvae were observed for 24 hours and mortality was calculated (Meyer et al., 1982). Seawater without biosurfactant was used as the control. Each test was run in triplicate.

\section{Assessment of phytotoxicity of industrial detergent}

Phytotoxicity of the detergent was evaluated in a static assay involving the cabbage species Brassica oleracea (var. capitata), with the analysis of seed germination and root growth, based on Tiquia et al. (1996). Test solutions of diluted detergent at proportions of 1:5 and 1:10 (v/v) were prepared in distilled water at concentrations of 1 and $2 \%$. Toxicity was determined in sterile Petri dishes $(10 \mathrm{~cm})$ containing Whatman No. 1 filter paper disks. Ten seeds (previously treated with $\mathrm{NaClO}$ ) were placed symmetrically in the dish, inoculated with $5 \mathrm{ml}$ of the test solution and maintained at $28^{\circ} \mathrm{C}$ for five days. Distilled water was used as a control. After incubation in the dark, seed germination, root growth $(\geq 5 \mathrm{~mm})$ and the germination index (GI) were calculated according to the formulas below:

Relative seed germination $(\%)=$ (number of seeds germinated in extract / number of seeds germinated in control) $\times 100$

Relative root length $(\%)=($ mean root length in extract $/$ mean root length in control $) \times 100$ $\mathrm{GI}=[(\%$ seed germination $) \times(\%$ root growth $)] / 100 \%$.

The mean and standard deviation of triplicate samples of each concentration were calculated. 
272 Application of detergent in cleaning of surfaces contaminated with heavy oil

273 The detergent formulated with the isolated biosurfactant was evaluated for heavy oil removal

274 from different types of contaminated surfaces, i.e., smooth surface (glass slide), metallic surface

275 (threaded nuts) and plastic surface (oil storage container). The heavy oil was obtained from a

276 thermoelectric power plant and classified as B1 Special OCB1 fuel oil (PETROBRAS, Brazil).

277 This oil is a complex mixture of hydrocarbons. Its kinematic viscosity at $60{ }^{\circ} \mathrm{C}$ is $620 \mathrm{Cst}$, its

278 flash point $66^{\circ} \mathrm{C}$ and its density at $20^{\circ} \mathrm{C} 0.968 \mathrm{~g} / \mathrm{mL}$. Part of the surface of a glass slide of

279 known mass was uniformly contaminated with $100 \mu \mathrm{L}$ of heavy oil. Metal nuts were completely

280 covered with OCB1 oil. Part of the outer surface of a plastic container was contaminated with

281

282

283

284

285

286

287

288

289

290

291

292

293

294

295

296

297

298

299

300

301

302

303

304

305

306

307

308

309

310

311

312

313

314

315

316

317

(pieces immersed in detergent at rest for three minutes). For the storage container, $100 \mathrm{~mL}$ of the detergent was manually spread on the surface and the oil was removed with the aid of absorbent material (sponge, paper towel, etc.). In this case, the percentage of removal was determined gravimetrically and visually. For the glass and metal, the specimens were oven dried at $40{ }^{\circ} \mathrm{C}$ for 30 minutes and the respective weights were recorded. The removal rate was calculated as follows:

$$
\mathrm{I}=100 \times\left(\left(\mathrm{W}_{\mathrm{c}}-\mathrm{W}_{\mathrm{w}}\right)\right) /\left(\left(\mathrm{W}_{\mathrm{c}}-\mathrm{W}_{\mathrm{i}}\right)\right)
$$

in which $\mathrm{W}_{\mathrm{c}}$ is the weight of the contaminated test specimen, $\mathrm{W}_{\mathrm{w}}$ is weight of the test specimen after washing and $\mathrm{W}_{\mathrm{i}}$ is the initial weight of the test specimen.

\section{Statistical analysis}

The data were submitted to statistical analysis using the one-way procedure in Statistica ${ }^{\circledR}$ (version 7.0), followed by linear one-way analysis of variance (ANOVA). All triplicate results were expressed as mean \pm standard deviation. Differences were examined using Tukey's post hoc test, with a $95 \%$ significance level.

\section{Results}

\section{Properties of biosurfactants}

In this work, bacteria capable of producing surfactants with the ability to mobilize and remove medium and heavy oils used at industrial plants were studied. The properties of the biosurfactants were evaluated and the reduction in the surface tension of the medium was the main parameter for the selection of surfactants.

\section{Reduction in surface tension}

The results obtained for biosurfactants produced by P. cepacia CCT 6659 in different media and culture conditions are shown in Figure 2.

The culture medium described by Soares da Silva et al. (2017) was used as a comparison to the media evaluated in the present study for the same strain, since $P$. cepacia proved to be an excellent biosurfactant producer in the study cited, achieving surface tension around $26 \mathrm{mN} / \mathrm{m}$.

The purpose of this initial stage was to study the most suitable culture media for the production of microbial surfactants considering the technical-economic feasibility of large-scale production and with the aim of increasing the yield with few downstream steps. The selection of the most favorable fermentation parameters for the production process was based on the determination of surface tension. For the biosurfactant obtained from the bacterium P. cepacia in the culture media analyzed, temperature exerted no significant influence on fermentation, 
318 although more satisfactory surface tension results were obtained at $37^{\circ} \mathrm{C}$. However, the most 319 promising result was obtained with the highest concentration of glucose $(3.0 \%)$ at $28{ }^{\circ} \mathrm{C}$, with

320

321

322

323

324

325

326

327

328

329

330

331

332

333

334

335

336

337

338

339

340

341

342

343

344

345

346

347

348

349

350

351

352

353

354

355

356

357

358

359

360

361

362

363

which surface tension of $31.60 \mathrm{mN} / \mathrm{m}$ was reached.

Figure 3 shows the results of the analysis of the biosurfactants produced by $P$. aeruginosa UCP 0992.

Temperature also did not exert an influence on the fermentation of $P$. aeruginosa UCP 0992. Lower concentrations of glucose and sucrose in the culture enabled a greater reduction in surface tension. The use of lower concentrations of substrates translates to an increase in the economy of the process due to the reduction in input costs, which is essential to increasing the market competitiveness of surfactants.

Figure 4 shows the surface tension reduction capacity of biosurfactants produced by the strains $P$. aeruginosa ATCC 10145 and P. aeruginosa ATCC 9027 at temperatures of 28 and 35 ${ }^{\circ} \mathrm{C}$. The mineral medium containing glycerol and glucose as carbon sources at the two temperatures evaluated was the most promising for the production of biosurfactants. As no significant difference was found between temperatures of 28 and $35^{\circ} \mathrm{C}$ during the $96 \mathrm{~h}$ of culture, $28{ }^{\circ} \mathrm{C}$ was considered more viable for obtaining biosurfactants due to the reduction in electricity costs, making the process more feasible.

The surface tension results obtained for the four microorganisms analyzed showed that the strains $P$. aeruginosa ATCC 10145 and P. aeruginosa ATCC 9027 achieved the best performance when cultivated in the medium containing $5 \%$ glycerol and $2 \%$ glucose carbon sources for 96 hours at $28^{\circ} \mathrm{C}$, reaching excellent surface tension values of around 25.00 and 29.00 , respectively. Thus, the biosurfactants produced by these two strains were selected for the evaluation of emulsification and dispersion capacity regarding hydrophobic compounds.

\section{Emulsification index}

The results of the emulsification activity tests of biosurfactants from $P$. aeruginosa ATCC 10145 and $P$. aeruginosa ATCC 9027 cultivated in the medium containing 5\% glycerol and $2 \%$ glucose for different hydrophobic compounds can be seen in Figure 5.

The biosurfactants from both strains exhibited good emulsification capacity for soybean, corn and motor oils, although with specific affinities for the different hydrophobic compounds evaluated. In general, the biosurfactants exhibited good emulsification efficiency for denser oils, especially motor oil, which is often used in industrial engines. The biosurfactant produced by $P$. aeruginosa ATCC 10145 emulsified $97.50 \%$ of the motor oil. Furthermore, the emulsions had relatively constant indices in relation to other less dense hydrophobic compounds, forming emulsions that remained stable in the long term.

\section{Dispersion capacity}

The dispersion capacity of microbial surfactants obtained from the strains $P$. aeruginosa ATCC 10145 and $P$. aeruginosa ATCC 9027 cultivated in the medium containing glycerol and glucose is shown in Figure 6.

The data demonstrated excellent dispersant activity. All biosurfactant/motor oil ratios tested were promising, especially the biosurfactant from $P$. aeruginosa ATCC 10145, which exhibited dispersion rates of approximately $99.00 \%$. The results indicate excellent interaction between the biosurfactants and oil, even at oil concentrations 25 -fold higher than that of the surfactants.

PeerJ reviewing PDF | (2021:08:64555:1:1:NEW 19 Oct 2021) 
364

365

366

367

368

369

370

371

372

373

374

375

376

377

378

379

380

381

382

383

384

385

386

387

388

389

390

391

392

393

394

395

396

397

398

399

400

401

402

403

404

405

406

407

408

\section{Critical Micelle Concentration}

Another important parameter for evaluating the efficiency of a biosurfactant is the $\mathrm{CMC}$, which is the minimum concentration of biosurfactant necessary for the maximum reduction in surface tension. In the present study, the biosurfactants isolated from the $P$. aeruginosa ATCC 10145 and $P$. aeruginosa ATCC 9027 strains exhibited excellent surfactant properties, yields and CMCs (Table 3 and Figure 7).

The yields are related to surfactants with low purity specifications, as industries that employ heavy oils does not require surfactants with a high degree of purification. Thus, downstream steps, which represent nearly $60 \%$ of total production costs, can be eliminated, making the use of biosurfactants economically advantageous (Santos et al., 2016).

The data demonstrate the considerable potential of the biosurfactants evaluated for oil removal purposes. From the results considering surface tension, the emulsification index and oil dispersion, P. aeruginosa ATCC 10145 was selected as the best biosurfactant producer. Thus, the biosurfactant produced by this bacterial strain was used as one of the main components in the formulation of a biodegradable detergent for application at industrial plants. In the culture medium containing $5.0 \%$ glycerol and $2.0 \%$ glucose as carbon sources, the biosurfactant from $P$. aeruginosa ATCC 10145 promoted intense foam formation (Figure 8A-B), indicating considerable emulsifying capacity.

Based on the results obtained, the biosurfactant produced from the selected strain under its best culture conditions was isolated, as described above. The yield was approximately $12 \mathrm{~g} / \mathrm{L}$. An increase in this yield can be achieved by optimizing the production parameters and studying upstream and downstream technologies for this biomolecule. The isolated biosurfactant was able to reduce the surface tension of water from $71 \mathrm{mN} / \mathrm{m}$ to $28 \mathrm{mN} / \mathrm{m}$ and form a very stable foam even when diluted (Figure 8).

\section{Isolation methods of selected biosurfactant}

The surface tension and yield of the biosurfactant from P. aeruginosa ATCC 10145 with different extraction methods results are described in Table 4 . The best reduction in surface tension of the cell-free broth and the liquid was achieved with the foam fractionation process. The best yield was achieved with foam fractionation and extraction using the chloroform/methanol system. Considering the need to obtain a low-cost surfactant with few downstream steps, the use of the broth and coalesced liquid proved to be more promising.

\section{Assessment of toxicity of industrial detergent}

Ecotoxicological tests using cabbage (Brassica oleracea) seeds and microcrustacean (Artemia salina) larvae as indicators demonstrated the absence of toxicity of the detergent formulated with the biosurfactant (Table 5). When compared to commercial detergents used in thermoelectric plants, the formulated detergent composed of $20 \%$ natural solvent, $2.0 \%$ thickening fatty alcohol, $0.5 \%$ stabilizing gum and $0.5 \%$ biosurfactant presented the same oil removal efficiency with no toxicity, which is a considerable advantage over commercial detergents. It is evident, therefore, that the biodetergent offers better working conditions for cleaning workers, ensuring a healthier environment due to the use of a harmless product.

\section{Application of industrial detergent in cleaning of surfaces contaminated with heavy oil}


409 Since the detergent formulation has several components, they were previously tested separately 410 for oil removal. These controls were carried out to show their effect on the oil removal efficiency. 411 Table 6 shows percentages of oil the removed by the detergent components. It can be observed 412 that the isolated biosurfactant has a similar efficiency when compared to the organic solvent. 413 After testing each component separately, different components concentrations were evaluated. 414 Among the various component concentrations studied, the best formulation was that containing $41520 \%$ natural solvent, $2.0 \%$ thickening fatty alcohol, $0.5 \%$ stabilizing gum and $0.5 \%$

416 biosurfactant. This combination of compounds formed a stable emulsion over the evaluation time 417 (one month) capable of removing heavy oil (OCB1) from different surfaces in a short time.

418 The detergent formulation was able to remove $100 \%$ of the heavy oil from a glass slide, threaded 419 nut and plastic surface (Figures. 9 and 10). The results indicate the benefit of the detergent and 420 that this formulation has potential for future use in the cleaning of parts, machines and equipment

421

422

423

424

425

426

427

428

429

430

431

432

433

434

435

436

\section{Discussion}

438

439

440

441

442

443

444

445

446

447

448

449

450

451

452

453 biosurfactant. impregnated with oils, greases and petroleum byproducts, such as OCB1 oil, commonly used in industrial plants. The green detergent could be a good solution for industrial cleaning, replacing the conventional products and solvents commonly used in such environments.

The selected formulation was also subjected to comparative tests with commercial detergents used in industrial plants, achieving very satisfactory results in the removal of OCB1 oil from metal surfaces through processes of solubilization and mobilization. Table 7 presents the results of the comparison of commercial detergents and the detergent formulated with the

The data demonstrated the potential of the green detergent for use in the removal of highdensity oil, such as OCB1 oil (heavy oil used as fuel for power generation at thermoelectric plants), the high viscosity of which constitutes an obstacle to the action of commercial detergents/mixtures. Although commercial detergent D achieved the same removal rate (100\%), one must bear in mind the considerable corrosive and volatile capacity of the product, which can harm the health of operators and limit the durability of metal parts. In contrast, the detergent formulated with the biosurfactant also achieved 100\% removal of the OCB1 oil.

Biosurfactant-producing bacteria are found in a wide variety of habitats from aquatic environments (fresh water, seawater and groundwater) to terrestrial environments (soil, sediment and silt). Environmental conditions exert a direct influence on the type of biosurfactants that microorganisms produce (Decho \& Gutierrez, 2017; Nikolova \& Gutierrez, 2021).

Bacteria of the genus Pseudomonas are able to produce different kinds of biosurfactants, including glycolipids (rhamnolipids) and lipopeptides. The most widely studied biosurfactant producer is $P$. aeruginosa, which produces rhamnolipids that form stable emulsions with hydrocarbons (Bollinger et al., 2020; Shahaliyan et al., 2015).

The production of biosurfactants by microbial species using renewable substrates and optimizing culture conditions (fermentation time, agitation speed, $\mathrm{pH}$ of the medium and nutrients) enables obtaining compounds with distinct properties that make these natural surfactants comparable or even superior to their synthetic counterparts (Silva et al., 2014). Indeed, the potential of bacteria of the genus Pseudomonas combined with the use of different media and fermentation conditions has enabled obtaining extremely promising biosurfactants in terms of surface tension reduction, dispersion and emulsifying capacity, which are fundamental properties in the selection of the biomolecule to compose a formulation with industrial purposes. 
454

455

456

457

458

459

460

461

462

463

464

465

466

467

468

469

470

471

472

473

474

475

476

477

478

479

480

481

482

483

484

485

486

487

488

489

490

491

492

493

494

495

496

497

498

499
The reduction in surface or interfacial tension is considered the main parameter for detecting a surface-active compound in a given production medium. This attraction force is the result of the joint interaction between the molecules of liquids. A potent biosurfactant decreases surface tension as its concentration increases in the aqueous medium, enabling greater interaction between immiscible liquids, such as oil and water (Silva et al., 2014). According to Eslami et al. (2020), a more than $8 \mathrm{mN} / \mathrm{m}$ reduction in surface tension is needed to identify a microorganism as a biosurfactant producer. However, rhamnolipids can reduce the surface tension of water from 72 to less than $30 \mathrm{mN} / \mathrm{m}$. In the present study, it was possible to obtain a biosurfactant with excellent surface tension reduction capacity through the different media and culture conditions tested with four bacterial strains, achieving values around $26.40 \mathrm{mN} / \mathrm{m}$.

The literature offers several studies on biosurfactants produced by species of Pseudomonas with similar properties to those obtained in this research. For instance, Patowary et al. (2017) produced a biosurfactant from the strain $P$. aeruginosa PG1 isolated from soil contaminated with hydrocarbons that reduced the surface tension of the culture medium from 51.80 to $29.60 \mathrm{mN} / \mathrm{m}$. Câmara et al. (2019) also obtained a biosurfactant from $P$. aeruginosa able to reduce the surface tension of water from 72.00 to $35.26 \mathrm{mN} / \mathrm{m}$. Using the strain $P$. aeruginosa NCIM 5514 cultivated in a medium with crude oil as the carbon source, Varjani \& Upasani (2019) produced a biosurfactant able to reduce the surface tension to $29.14 \pm 0.05$ $\mathrm{mN} / \mathrm{m}$.

Most microbial surfactants are substrate specific, solubilizing or emulsifying different hydrocarbons at different rates. The inability to emulsify some hydrocarbons may be due to the inability of the biosurfactant to stabilize microscopic droplets (Bouassida et al., 2018). In this work, the biosurfactant from $P$. aeruginosa ATCC 10145 exhibited considerable affinity with motor oil, as demonstrated by the emulsification rates higher than $97 \%$ obtained for this substrate. In contrast, the vegetable oils tested were not emulsified to the same degree, although $50 \%$ of these oils were also stably emulsified by the biomolecule. This affinity with motor oil is related to the chemical structure of the biosurfactants evaluated (Sousa et al., 2014), which enables greater intermolecular interaction with the chemical structure of the oil, making these microbial surfactants suitable for applications in industrial environments that generate mineral oil waste (Almeida et al., 2016). Anaukwu et al. (2020) described the optimization of biosurfactant production by $P$. aeruginosa to determine the impact of different renewable waste products. The preferred carbon source of the bacterial isolate was sugarcane molasses. The biosurfactant achieved an emulsification index of $96.3 \% \pm 0.75 \%$. In the study by Bezerra et al. (2020), the emulsification index of a biosurfactant from $P$. aeruginosa reached $71.0 \%$ for vegetable oils.

Another important parameter for evaluating the efficiency of a biosurfactant is the CMC, which is the minimum concentration of biosurfactant necessary for the maximum reduction in surface tension. The increase in the concentration of a surfactant in the medium promotes the formation of micelles, which are aggregated amphipathic molecules with the hydrophilic portion positioned outwards and hydrophobic portion positioned inwards, enabling the trapping of oil in the micellar complex and promoting emulsification (Arsene et al., 2021). The CMC is another important parameter to consider in the development of large-scale production processes, as it enables the prediction of efficiency and economic viability (Santos et al., 2016). The CMC found for the biosurfactants from P. aeruginosa ATCC 10145 and ATCC 9027 were higher than many values described in the literature for potent bacterial surfactants, such as the biosurfactant produced by $P$. aeruginosa S5, which had a CMC of $96.50 \mathrm{mg} / \mathrm{L}$ and reduced surface tension

PeerJ reviewing PDF | (2021:08:64555:1:1:NEW 19 Oct 2021) 
500 from 72.20 to $29.60 \mathrm{mN} / \mathrm{m}$ (Sun et al., 2019). Similar results were also found in the work by 501 Anaukwu et al. (2020), with the surface tension of distilled water reduced from $72.10 \mathrm{mN} / \mathrm{m}$ to $50235.00 \pm 0.0 \mathrm{mN} / \mathrm{m}$ and a CMC of $60.00 \mathrm{mg} / \mathrm{L}$.

$503 \quad$ Although biosurfactant isolation techniques still need to be improved, the yields obtained

504 for $P$. aeruginosa biosurfactants in this work were satisfactory when compared to those

505 described in the literature for other microbial biosurfactants. The yields obtained are related to

506 surfactants with low purity specifications, as industries that employ heavy oils does not require 507 surfactants with a high degree of purification. Thus, downstream steps, which represent nearly

$50860 \%$ of total production costs, can be eliminated, making the use of biosurfactants economically 509 advantageous.

An oil dispersant consists of a mixture of various chemicals, but the major

512

513

514

515

516

517

518

519

520

521

522

523

524

525

526

527

528

529

530

531

532

533

534

535

536

537

538

539

540 constituents are surfactants, which are responsible for solubilization and dispersion. Due to their amphipathic structure, surfactants solubilize oil through the formation of micelles, which disperse in water (Silva et al., 2014). Corexit is one of the most widely used chemical dispersants for oil solubilization. This chemical agent passed initial testing by the US Environmental Protection Agency (EPA) after the government asked to cut its use in half. For the test, the EPA analyzed eight chemicals to determine how oil dispersants affect marine wildlife. All products had negative effects despite the favorable dispersant performance. The EPA still permits the use of Corexit but stresses the need to find a more environmentally friendly alternative (Silva et al., 2014). In this scenario, biosurfactants constitute a promising alternative to replace chemical dispersants in formulations. The dispersion results obtained in the present study for biosurfactants from the strains P. aeruginosa ATCC 10145 and ATCC 9027 were above 70\% regardless of the type of oil and dilution tested and reached rates of up to $95 \%$, demonstrating the capacity of these biomolecules as dispersing agents. Other biosurfactants produced by species of Pseudomonas have proven to be highly efficient dispersants of petroleum byproducts. Soares $d a$ Silva et al. (2017) demonstrated that the biosurfactant from P. cepacia dispersed oil (81\%), indicating the potential of the biosurfactant for application in the control of oil spills. Sun et al. (2019) proved that the glycolipid biosurfactant produced by a strain of $P$. aeruginos $a$ was able to disperse approximately $74 \%$ of petroleum byproduct in water. A new green detergent similar to the formulation described in this work, composed by $1.0 \%$ of the biosurfactant from Starmerella bombicola ATCC $22214,0.4 \%$ of hydroxyethyl cellulose, $1.0 \%$ of EDTA and $0.2 \%$ of potassium sorbate as preservative was tested in the remediation of soils contaminated with hydrocarbons (Silva et al., 2021). The formulation showed effectiveness in removing motor oil from contaminated sandy soil (80.0\%) and beach sand (65.0\%) under static conditions. Although the conditions applied were totally different form the experiments carried out in our research, the static condition can be compared to the immersion tests carried out for heavy oil removal and shows, once more, the feasibility of detergent formulations based on biosurfactants.

Studies have reported that some forms of extraction and isolation are more adequate for specific biosurfactants. In the present study, three forms of isolation were evaluated for the biosurfactant from $P$. aeruginosa ATCC 10145 to select the most economically viable extraction method capable of obtaining the highest concentration of biosurfactant for application in the

541 formulation of the detergent. The most promising isolation method was foam fractionation.

542 Several studies in the literature report the characteristics of the foaming method of biosurfactants 543 in fermentation broths and the use of foaming for product recovery. Beuker et al. (2016) 544 evaluated the efficacy of foam fractionation in rhamnolipid production. The foam fractionation 545 process was easily manageable in an enriched bioreactor and the biosurfactants were highly 
546 concentrated in the foam during the culture process, with an increase in rhamnolipid recovery of

547 up to $97 \%$. Bages-Estopa et al. (2018) used the foaming method for trehalolipid biosurfactants in 548 fermentation broths. Trehalolipids were produced by the bacterium Rhodococcus sp. PML026

549 with hexadecane as carbon source. Hexadecane suppresses foaming during fermentation, which

550 is beneficial during the growth and production phases. In the study, the hexadecane substrate was

551

552

553

554

555

556

557

558

559

560

561

562

563

564

565

566

567

568

569

570

571

572

573

574

575

576

577

578

579

580

581

582

583

584

585

586

587

588

589

590

591 exhausted at the end of the fermentation, enabling the formation of foam and the separation of the product by foam fractionation, with a total trehalolipid recovery rate of 23 to $58 \%$. Blesken et al. (2020) proposed this method as a pre-purification step. Foam fractionation was coupled to the bioreactor operation using an external fractionation column to decouple the production of a rhamnolipid by $P$. putida KT2440. The technique enabled continuous separation of the surfactant, which is particularly suitable for scale-up. Surfactant concentrations of $7.50 \mathrm{~g} / \mathrm{L}$ were obtained in the fractionated foam. These studies demonstrate a strategic, low cost, eco-friendly technology for separating biosurfactants from emulsified fermentation broths.

The absence of toxicity is of fundamental importance for the application of a product in industrial sectors. Detergents and surfactants are among the most widely used chemicals in industries. The toxic effect of a detergent depends on its mode of action, the toxicity of the active ingredient (surfactant) and the response of organisms. Short-term ecotoxicity bioassays are analytical methods that enable the assessment of bioavailability and the toxicity of chemical substances by showing acute effects on the survival or mobility of test organisms. The toxicity tests conducted in the present study revealed the non-toxic nature of the detergent formulated with the $P$. aeruginosa biosurfactant ATCC1045, demonstrating the viability of this novel product in the market. The detergent formulation produced in this work also achieved better results in comparison to microbial biosurfactants described in the literature (Ostendorf et al., 2019; Rocha e Silva et al., 2014).

The literature describes several studies conducted to determine the toxicity of chemical detergents on test organisms, but little is known about the toxic effects of biobased detergents, which are considered to be environmentally friendly. Uc-Peraza \& Delgado-Blas (2015) studied the toxicity of three commercial detergent formulations (ROMA ${ }^{\circledR}$, FOCA ${ }^{\circledR}$ and BLANCA NIEVES $\left.{ }^{\circledR}\right)$ to determine the median lethal concentration $\left(\mathrm{LC}_{50}\right)$. FOCA ${ }^{\circledR}$ was the most toxic detergent, followed by BLANCA NIEVES ${ }^{\circledR}$ and ROMA ${ }^{\circledR}$. According to the authors, the difference in toxicity among the three detergents can be related to the concentrations of the anionic surfactants or to other ingredients such as sodium silicate, enzymes, sodium tripolyphosphate, bleaches and perfumes. In acute toxicity tests with fish, Baharuddin et al. (2020) found that a dispersant based on water and ionic liquids (ILs) [1-butyl-3methylimidazolium lauroylsarcosinate, 1,1'-(1,4-butanediyl)bis (1-H-pyrrolidinium) dodecylbenzenesulfonate, tetrabutylammonium citrate, tetrabutylammonium polyphosphate and tetrabutylammonium ethoxylate oleyl ether glycolate] was practically non-toxic and exhibited excellent biodegradability throughout the test period. This novel surfactant was considered an oil facilitator and environmentally safe for use in oil spill remediation process and could effectively replace toxic chemical dispersants. Rocha and Silva et al. (2020) developed a sustainable plantbased biodetergent composed of a natural solvent (cotton seed oil), plant surfactant agent (saponin) and two natural stabilizers (carboxymethylcellulose and glycerin), which exhibited stability, efficiency (removing 100\% of heavy oil from metallic surfaces) and the absence of toxicity. According to the authors, the application of the novel product would reduce both environmental impact and the risk posed to worker health related to toxic cleaning products. Arpornpong et al. (2020) investigated improved washing technology to treat drill cuttings from

Peer) reviewing PDF | (2021:08:64555:1:1:NEW 19 Oct 2021) 
592 oil exploration and production sites with high concentrations of total petroleum hydrocarbons 593 (TPHs). For such, a biologically based washing agent was formulated with a lipopeptide 594 biosurfactant (in foam or cell-free broth), Dehydol LS7TH (fatty alcohol ethoxylate 7EO - an oleochemical surfactant) and butanol (as a lipophilic binder) in water. Due to the synergistic behavior between the anionic lipopeptides and the nonionic Dehydol LS7TH, the formula removed $92 \%$ of the TPHs from the drill cuttings when applied in a test jar. In a study conducted

598

599

600

601 by Helmy et al. (2020), the application of biosurfactants in the formulation of a washing detergent was investigated and compared to that of a standard commercial detergent. The formulation comprising a mixture of a rhamnolipid, sodium tripolyphosphate as a builder and sodium sulphate as a filler was applied to wash stained cotton fabric. The results showed that the

602

603 biosurfactant and its formulations are a promising substitute for synthetic counterparts, as for the results obtained in this work.

Therefore, biobased detergents are efficient and sustainable. In addition to promoting

604

605

606

607

608

609

610

\section{Conclusions}

612 Advances in sustainable technologies have increasingly driven the search for natural

613 biodegradable compounds that can achieve direct and indirect reductions in impacts on the

614 environment, such as green formulations based on microbial surfactants. The biosurfactant from

615 P. aeruginosa ATCC 10145 demonstrated viability for the formulation of a non-toxic detergent,

616 with a high capacity to remove heavy oil impregnated on different surfaces. Thus, the present

617 results demonstrate an innovative product that is superior in efficiency compared to chemical

618 detergents currently on the market and is capable of reducing the environmental impacts arising

619 from contamination by heavy oils. Since this is a laboratory study, viability for industrial

620 application needs large-scale studies. Other parameters, such as aroma, color and long-term

621 stability, also need to be considered. A future, more in-depth investigation with the on-site

622 application of this novel product could indicate more applications in common industrial

623 activities.

624

625

626

627

628

629

630

631

632

633

634

635

\section{Acknowledgements}

The authors are grateful to the laboratories of the Icam Tech School of the Catholic University of Pernambuco (UNICAP) and the Advanced Institute of Technology and Innovation (IATI), Brazil. Authors also like to thank Lucas Rocha for his technical assistance.

\section{References}

\section{Almeida DG, Soares da Silva RCF, Luna JM, Rufino RD, Santos VA, Banat IM, Sarubbo}

LA. 2016. Biosurfactants: Promising molecules for petroleum biotechnology advances. Frontiers in Microbiology 7:1718. DOI 10.3389/fmicb.2016.01718.

Anaukwu CG, Ogbukagu CM, Ekwealor IA. 2020. Optimized biosurfactant production by Pseudomonas aeruginosa strain CGA1 using agro-industrial waste as sole carbon source. Advances in Microbiology 10(10):543-562. DOI 10.4236/aim.2020.1010040. 
636

637

638

639

640

641

642

643

644

645

646

647

648

649

650

651

652

653

654

655

656

657

658

659

660

661

662

663

664

665

666

667

668

669

670

671

672

673

674

675

676

677

678

679

680

Arpornpong N, Padungpol R, Khondee N, Tongcumpou C, Soonglerdsongpha S, Suttiponparnit K, Luepromchai E. 2020. Formulation of bio-based washing agent and its application for removal of petroleum hydrocarbons from drill cuttings before bioremediation. Frontiers in Bioengineering and Biotechnology 8:961. DOI 10.3389/fbioe.2020.00961.

Arsene M-L, Răut I, Călin M, Jecu M-L, Doni M, Gurban A-M. 2021. Versatility of reverse micelles: from biomimetic models to nano (bio)sensor design. Processes 9(2):345. DOI g/10.3390/pr9020345.

Bages-Estopaa S, White DA, Winterburna JB, Webba C, Martina PJ. 2018. Production and separation of a trehalolipid biosurfactant. Biochemistry Engineering Journal 139(15):85-94. DOI 10.1016/j.bej.2018.07.006.

Baharuddin SH, Mustahil NA, Reddy AVB, Abdullah AA, Mutalib MIA, Moniruzzaman M. 2020. Development, formulation and optimization of a novel biocompatible ionic liquids dispersant for the effective oil spill remediation. Chemosphere 249:126125. DOI 10.1016/j.chemosphere.2020.126125.

Beuker J, Steier A, Wittgens A, Rosenau F, Henkel M, Hausmann R. 2016. Integrated foam fractionation for heterologous rhamnolipid production with recombinant Pseudomonas putida in a bioreactor. $A M B$ Express 6(11):11. DOI 10.1186/s13568-016-0183-2.

Bezerra KGO, Rufino R D, Luna JM, Sarubbo LA. 2018. Saponins and microbial biosurfactants: potential raw materials for the formulation of cosmetics. Biotechnology Progress 34(6):1482-1493 DOI 10.1002/btpr.2682.

Bezerra KGO, Durval IJB, Silva IA, Almeida FCG, Melo YTF, Rufino RD, Sarubbo LA. 2020. Emulsifying capacity of biosurfactants from Chenopodium Quinoa and Pseudomonas Aeruginosa UCP 0992 with Focus of application in the cosmetic industry. Chemical Engineering Transactions 79:211-216. DOI 10.3303/CET2079036.

Bollinger A, Thies S, Katzke N, Jaeger KE 2020. The biotechnological potential of marine bacteria in the novel lineage of Pseudomonas pertucinogena. Microbial Biotechnol. 13(1):1931. DOI 10.1111/1751-7915.13288.

Bouassida M, Ghazala I, Ellouze-Chaabouni S, Ghribi D. 2018. Improved biosurfactant production by Bacillus subtilis SPB1 mutant obtained by random mutagenesis and its application in enhanced oil recovery in a sand system. Journal of Microbiology and Biotechnology 28(1):95-104. DOI 10.4014/jmb.1701.01033.

Blesken CC, Strümpfler T, Tiso T, Blank LM 2020. Uncoupling foam fractionation and foam adsorption for enhanced biosurfactant synthesis and recovery. Microorganisms 8(12):2029. DOI 10.3390/microorganisms8122029.

Câmara JMDA, Sousa MASB, Barros Neto EL, Oliveira MCA. 2019. Application of rhamnolipid biosurfactant produced by Pseudomonas aeruginosa in microbial-enhanced oil recovery (MEOR). Journal of Petroleum Exploration and Production Technology 9:23332341. DOI 10.1007/s13202-019-0633-X

Cooper DG, Goldenberg BG. 1987. Surface-active agents from two bacillus species. Applied and Environmental Microbiology 53(2):224-229. DOI 0099-2240/87/020224-06\$02.00/0.

Dave D, Ghaly A. 2011. Remediation technologies for marine oil spills: a critical review and comparative analysis. American Journal of Environmental Science, 7(5):424-440. DOI 10.3844/ajessp.2011.424.440

Drakontis CE, Amin S. 2020. Biosurfactants: Formulations, properties, and applications. Current Opinion in Colloid \& Interface Science 48:77-90, DOI 10.1016/j.cocis.2020.03.013.

Peer] reviewing PDF | (2021:08:64555:1:1:NEW 19 Oct 2021) 
681 Decho AW, Gutierrez T. 2017. Microbial extracellular polymeric substances (EPSs) in ocean

682

683

684

685

686

687

688

689

690

691

692

693

694

695

696

697

698

699

700

701

702

703

704

705

706

707

708

709

710

711

712

713

714

715

716

717

718

719

720

721

722

723

724

725

726 systems. Frontiers in Microbiology 8:922. DOI 10.3389/fmicb.2017.00922.

Eslami P, Hajfarajollah H, Bazsefidparc S. 2020. Recent advancements in the production of rhamnolipid biosurfactants by Pseudomonas aeruginosa. RSC Advances 10(56):34014. DOI 10.1039/d0ra04953k.

Farias CBB, Almeida FCG, Silva IA, Souza TC, Meira HM, Soares da Silva RCF, Luna JM, Santos VA, Converti A, Banat IM, Sarubbo LA. 2021. Production of green surfactants: Market prospects. Electronic Journal of Biotechnology 51:28-39. DOI 10.1016/j.ejbt.2021.02.002.

Helmy Q, Gustiani S, Mustikawat AT. 2020. Application of rhamnolipid biosurfactant for biodetergent formulation. IOP Conf. Ser.: Materials Science and Engineering 823:012014. DOI 10.1088/1757-899X/823/1/012014.

Jian H-l, Liao X-x, Zhu L-w, Zhang W-m, Jiang J-x. 2011. Synergismand foaming properties in binary mixtures of a biosurfactant derived from Camellia oleifera Abel and synthetic surfactants. Journal of Colloid and Interface Science 359:487-492.

DOI 10.1016/j.jcis.2011.04.038

Jimoh AA, Lin J. 2019. Biosurfactant: A new frontier for greener technology and environmental sustainability. Ecotoxicology and Environmental Safety 184:109607. DOI 10.1016/j.ecoenv.2019.109607.

Jin L, Garamus VM, Liu F, Xiao J, Eckerlebe H, Willumeit-Römer R, Mu B, Zou A. 2016. Interaction of a biosurfactant, surfactin with a cationic gemini surfactant in aqueous solution. Journal of Colloid and Interface Science 481:201-209. DOI 10.1016/j.jcis.2016.07.044

Markande AR, Patel D, Varjani S. 2021. A review on biosurfactants: properties, applications and current developments. Bioresource Technology 330:124963. DOI 10.1016/j.biortech.2021.124963.

Meyer B, Ferrigni NR, Putnam JE, Jacobsen LB, Nichols DE, McLaughlin JL. 1982. Brine Shrimp: A convenient general bioassay for active plant constituents. Planta Medica 45(5):3134. DOI 10.1055 / s-2007-971236.

Nikolova C, Gutierrez T. 2021. Biosurfactants and their applications in the oil and gas industry: current state of knowledge and future perspectives. Frontiers in Bioengineering and Biotechnology 9:46. DOI 10.3389/fbioe.2021.626639.

Ostendorf TA, Silva IA, Converti A, Sarubbo LA. 2019. Production and formulation of a new low-cost biosurfactant to remediate oil-contaminated seawater. Journal of Biotechnology 295:71-79. DOI 10.1016/j.jbiotec.2019.01.025

Patowary K, Patowary R, Kalita MC, Deka S. 2017. Characterization of biosurfactant produced during degradation of hydrocarbons using crude oil as sole source of carbon. Frontiers in Microbiology 8:279. DOI 10.3389/fmicb.2017.00279.

Plaza G, Achal V. 2020. Biosurfactants: Eco-friendly and innovative biocides against biocorrosion. International Journal of Molecular Sciences 21:2152; DOI 10.3390/ijms21062152.

Rocha e Silva NMP, Almeida FCG, Rocha e Silva FCP, Luna JM, Sarubbo LA. 2020. Formulation of a biodegradable detergent for cleaning oily residues generated during industrial processes. Journal of Surfactants and Detergents 23(6):11-1123. DOI 10.1002/jsde. 12440.

Rocha e Silva NMP, Meira HM, Almeida FCG, Soares da Silva RCF, Almeida DG, Luna JM, Rufino RD, Santos VA, Sarubbo LA. 2019. Natural surfactants and their applications

PeerJ reviewing PDF | (2021:08:64555:1:1:NEW 19 Oct 2021) 
for heavy oil removal in industry. Separation and Purification Reviews 48(4):267-281. DOI 10.1080/15422119.2018.1474477.

Rocha e Silva NMP, Rufino RD, Luna JM, Santos VA, Sarubbo LA. 2014. Screening of Pseudomonas species for biosurfactant production using low-cost substrates. Biocatalysis and Agricultural Biotechnology 3:132-139. DOI 10.1016/j.bcab.2013.09.005

Rongsayamanont W, Soonglerdsongpha S, Khondee N, Pinyakong O, Tongcumpou C, Sabatini DA, Luepromchai E. 2017. Formulation of crude oil spill dispersants based on the HLD concept and using a lipopeptide biosurfactant. Journal of Hazardous Materials 334: 168-177. DOI 10.1016/j.jhazmat.2017.04.005.

Saeki H, Sasaki M, Komatsu K, Miura A. 2009. Hitoshi matsuda oil spill remediation by using the remediation agent JE1058BS that contains a biosurfactant produced by Gordonia sp. strain JE-1058. Bioresource Technology 100(2):572-577. DOI 10.1016/j.biortech.2008.06.046.

Santos DKF, Luna JM, Rufino RD, Santos VA, Sarubbo LA. 2016. Biosurfactants: multifunctional biomolecules of the 21st Century. International Journal of Molecular Sciences 17(3):401-430 DOI 10.3390/ijms17030401.

Shah M.UH, Moniruzzaman M, Sivapragasam M, Talukder MMR, Yusup SB, Goto M. 2019. A binary mixture of a biosurfactant and an ionic liquid surfactant as a green dispersant for oil spill remediation. Journal of Melecular Liquids 280:111-119. DOI 10.1016/j.molliq.2019.02.049

Shah MUH, Sivapragasam M, Moniruzzaman M, Yusup SBt. 2016. A comparison of recovery methods of rhamnolipids produced by Pseudomonas Aeruginosa. Procedia Engineering 148:494-500. DOI 10.1016/j.proeng.2016.06.538.

Shahaliyan F, Safahieh A, Abyar H. 2015. Evaluation of emulsification index in marine bacteria Pseudomonas sp. and Bacillus sp. Arabian Journal of Science and Engineering 40:1849-1854. DOI 10.1007/s13369-015-1663-4.

Silva MGC, Sarubbo LA. 2021. Synthetic and biological surfactants used to mitigate biofouling on industrial facilities surfaces. Biointerface Research in Applied Chemistry 12(2):2560 - 2585. DOI 10.33263/BRIAC122.25602585.

Silva IGS, de Almeida FCG, Rocha e Silva NMP, Oliveira JTR, Converti A, Sarubbo LA. 2021. Application of green surfactants in the remediation of soils contaminated by hydrocarbons. Processes, 9:1666. DOI 10.3390/pr9091666

Silva RCFS, Almeida DG, Rufino RD, Luna JM, Santos VA, Sarubbo LA. 2014. Applications of biosurfactants in the petroleum industry and the remediation of oil spills. International Journal of Molecular Science 15(7):12523-12542. DOI 10.3390/ijms150712523.

Silva SNRL, Farias CBB, Rufino RD, Luna JM, Sarubbo LA. 2010. Glycerol as substrate for the production of biosurfactant by Pseudomonas aeruginosa UCP0992. Colloids and Surfaces B: Biointerfaces 79(1):174-183. DOI 10.1016/j.colsurfb.2010.03.050.

Soares da Silva RCF, Almeida DG, Meira HM, Silva EJ, Farias CBB, Rufino RD, Luna JM, Sarubbo LA. 2017. Production and characterization of a new biosurfactant from Pseudomonas cepacia grown in low-cost fermentative medium and its application in the oil industry. Biocatalysis and Agricultural Biotechnology 12:206-215. DOI 10.1016/j.bcab.2017.09.004. 
771

772

773

774

775

776

777

778

779

780

781

782

783

784

785

786

787

788

789

790

791

792

793

794

795

796

797

798

799

800

801

802

803

804

805

806

807
Song D, Liang S, Zhang Q, Wang J, Yan L. 2013. Development of high efficient and low toxic oil spill dispersants based on sorbitol derivants nonionic surfactants and glycolipid biosurfactants. Journal of Environmental Protection 4:16. DOI 10.4236/jep.2013.41b004

Sousa M, Dantas IT, Feitosa FX, Alencar AEV, Soares SA, Melo VMM, Gonçalves LRB, Sant'ana HB. 2014. Performance of a biosurfactant produced by Bacillus subtilis LAMI005 on the formation of oil / biosurfactant / water emulsion: study of the phase behaviour of emulsified systems. Brazilian Journal of Chemical Engineering 31(3):613 - 623. DOI 10.1590/0104-6632.20140313s00002766.

Sun S, Wang Y, Zang T, Wei J, Wu H, Wei C, Qiu G, Li F. 2019. A biosurfactant-producing Pseudomonas aeruginosa S5 isolated from coking wastewater and its application for bioremediation of polycyclic aromatic hydrocarbons. Bioresource Technology 281:421-428. DOI 10.1016/j.biortech.2019.02.087.

Tiquia SM, Tam NFY, Hodgkiss IJ. 1996. Effects of composting on phytotoxicity of spent pigmanure sawdut litter. Environmental Pollution 93(3):249-256. DOI 10.1016/S02697491(96)00052-8.

Thomas GE, Brant JL, Campo P, Clark DR, Coulon F, Gregson BH, McGenity TJ, McKew BA. 2021. Effects of dispersants and biosurfactants on crude-oil biodegradation and bacterial community succession. Microorganisms 9:1200. DOI 10.3390/microorganisms9061200

Uc-Peraza RG, Delgado-Blas VH. 2015. Acute toxicity and risk assessment of three comercial detergents using the polychaete Capitella sp. C from Chetumal Bay, Quintana Roo, Mexico. International Aquatic Research 7:251-261. DOI 10.1007/s40071-015-0112-z.

Varjani S, Upasani VN. 2019. Evaluation of rhamnolipid production by a halotolerant novel strain of Pseudomonas aeruginosa. Bioresource Technology 288:121577. DOI 10.1016/j.biortech.2019.121577.

Varjani S, Upasani VN, Pandey A. 2020. Bioremediation of oily sludge polluted soil employing a novel strain of Pseudomonas aeruginosa and phytotoxicity of petroleum hydrocarbons for seed germination. Science of the Total Environment 737:139766. DOI 10.1016/j.scitotenv.2020.139766.

Winterburn JB, Russell AB, Martin PJ. 2011. Integrated recirculating foam fractionation for the continuous recovery of biosurfactant from fermenters. Biochemical Engineering Journal 54(2):132-139. DOI 10.1016/j.bej.2011.02.011.

Zhu Z, Zhang B, Cai Q, Ling J, Lee K, Chen B. 2020. Fish waste based lipopeptide production and the potential application as a bio-dispersant for oil spill control. Frontiers in Bioengineering and Biotechnology 8:1-16. DOI 10.3389/fbioe.2020.00734 


\section{Table $\mathbf{1}$ (on next page)}

Media and culture conditions evaluated for production of biosurfactants by strains of Pseudomonas. 
Production media and fermentation conditions

\section{Microorganisms}

\section{Carbon sources}

\section{Cultivation parameters}

\begin{tabular}{|c|c|c|}
\hline \multirow{5}{*}{ Pseudomonas cepacia CСТ6659 } & $\begin{array}{l}2.0 \% \text { canola frying oil and } 3.0 \% \text { corn steep } \\
\text { liquor (Soares da Silva et al., 2013) }\end{array}$ & $\begin{array}{l}\mathrm{pH} 7.0 ; 250 \mathrm{rpm} ; \\
60 \mathrm{~h} ; 28 \text { and } 37^{\circ} \mathrm{C}\end{array}$ \\
\hline & $5.0 \%$ glycerol and $2.0 \%$ glucose & \multirow{4}{*}{$\begin{array}{l}\mathrm{pH} 7.0 ; 200 \mathrm{rpm} ; \\
96 \mathrm{~h} ; 28 \text { and } 37^{\circ} \mathrm{C}\end{array}$} \\
\hline & $1.5 \%$ glucose & \\
\hline & $2.0 \%$ glucose & \\
\hline & $3.0 \%$ glucose & \\
\hline \multirow{5}{*}{$\begin{array}{l}\text { Pseudomonas aeruginosa } \\
\text { UCP0992 }\end{array}$} & $1.5 \%$ glucose & \multirow{5}{*}{$\begin{array}{l}\mathrm{pH} 7.0 ; 200 \mathrm{rpm} ; \\
96 \mathrm{~h} ; 28 \text { and } 37^{\circ} \mathrm{C}\end{array}$} \\
\hline & $2.0 \%$ glucose & \\
\hline & $3.0 \%$ glucose & \\
\hline & $2.0 \%$ sucrose & \\
\hline & $3.0 \%$ sucrose & \\
\hline
\end{tabular}

$5.0 \%$ glycerol and $2.0 \%$ glucose

Pseudomonas aeruginosa ATCC 9027 and Pseudomonas aeruginosa ATCC 10145
$1.0 \% \mathrm{~N}$-hexadecane and $1.0 \%$ glucose $\mathrm{pH} 7.0 ; 200 \mathrm{rpm}$; $2.0 \%$ sugar cane molasses and $3.0 \%$ corn steep liquor 
Table 2 (on next page)

Compounds evaluated for formulation of industrial detergent containing biosurfactant. 


\begin{tabular}{lc}
\hline Components & Quantities (\%) \\
\hline Natural organic solvent (v/v) & 20.0 and 30.0 \\
Isolated biosurfactant (w/v) & 0.5 and 1.0 \\
Thickener fatty alcohol (w/v) & $0.5,1.5,2.0,2.5$ and 3.0 \\
Stabilizing gum (w/v) & $0.4,0.5$ and 0.6 \\
\hline
\end{tabular}

1 


\section{Table 3 (on next page)}

Properties of biosurfactants from $P$. aeruginosa ATCC 10145 and $P$. aeruginosa ATCC 9027 cultivated in medium composed of $5.0 \%$ glycerol and $2.0 \%$ glucose for $96 \mathrm{~h}$ at $28^{\circ} \mathrm{C}$. 


\begin{tabular}{lccc}
\hline \multicolumn{1}{c}{ Microorganisms } & $\begin{array}{c}\text { Surface tension } \\
(\mathbf{m N} / \mathbf{m})\end{array}$ & $\begin{array}{c}\text { CMC } \\
(\mathbf{m g} / \mathbf{L})\end{array}$ & $\begin{array}{c}\text { Yield } \\
(\mathbf{g} / \mathbf{L})\end{array}$ \\
\hline Pseudomonas aeruginosa ATCC 9027 & $28.00 \pm 0.37$ & 20.00 & $1.20 \pm 0.08$ \\
Pseudomonas aeruginosa ATCC 10145 & $26.40 \pm 0.32$ & 60.00 & $11.97 \pm 0.29$ \\
\hline
\end{tabular}

1 


\section{Table 4 (on next page)}

Surface tension and yield of biosurfactant from $P$. aeruginosa ATCC 10145 cultivated in medium composed of $5.0 \%$ glycerol and $2.0 \%$ glucose with different extraction methods. 


\section{Biosurfactant and extraction methods $\quad$ Surface tension $(\mathrm{mN} / \mathrm{m}) \quad$ Yield $(\mathrm{g} / \mathrm{L})$}

Cell-free broth (crude biosurfactant) $\quad 24.06 \pm 0.22$

$\begin{array}{lll}\text { Biosurfactant isolated with chloroform/methanol } & 30.60 \pm 0.13 & 1.82 \pm 0.02\end{array}$

Biosurfactant isolated by acid precipitation

$29.43 \pm 0.15$

$0.44 \pm 0.00$

Biosurfactant isolated by foam fractionation

$26.50 \pm 0.22$

$11.45 \pm 0.21 \% *$ 


\section{Table 5 (on next page)}

Toxicity tests of detergent formulated with $20 \%$ natural solvent, $2.0 \%$ thickening fatty alcohol, $0.5 \%$ stabilizing gum and $0.5 \%$ biosurfactant from $P$. aeruginosa ATCC 10145 . 


\begin{tabular}{ccc}
\hline $\begin{array}{c}\text { Detergent/water ratio } \\
(\mathbf{v} / \mathbf{v})\end{array}$ & $\begin{array}{c}\text { Mortality of } \text { Artemia } \\
\text { salina larvae (\%) }\end{array}$ & $\begin{array}{c}\text { Brassica oleracea seed } \\
\text { germination (\%) }\end{array}$ \\
\hline $1 / 5$ & $10.00 \pm 0.01$ & $100.00 \pm 0.01$ \\
$1 / 10$ & No mortality & $100.00 \pm 0.00$ \\
\hline
\end{tabular}

1 


\section{Table 6(on next page)}

Removal of heavy oil (OCB1) from glass slide by the components of detergent formulated with biosurfactant from $P$. aeruginosa ATCC 10145 cultivated in $5.0 \%$ glycerol and $2.0 \%$ glucose for $96 \mathrm{~h}$ at $28^{\circ} \mathrm{C}$. 


\begin{tabular}{lc}
\hline Formulation components & Oil removal \\
\hline Natural organic solvent & $40 \pm 0.51 \%$ \\
Isolated biosurfactant & $40 \pm 0.37 \%$ \\
Thickener fatty alcohol & $25 \pm 0.13 \%$ \\
\hline
\end{tabular}

1 


\section{Table 7 (on next page)}

Removal of heavy oil from metal surfaces by commercial detergents and detergent formulated with biosurfactant from $P$. aeruginosa ATCC10145 cultivated in $5.0 \%$ glycerol and $2.0 \%$ glucose for $96 \mathrm{~h}$ at $28^{\circ} \mathrm{C}$. 
Detergents

Water (control)

Commercial detergent A

Commercial detergent B

Commercial detergent $\mathrm{C}$

Commercial detergent D

Detergent formulated with biosurfactant

\section{Removal of OCB1 heavy oil (\%)}

$$
\begin{gathered}
2.10 \pm 0.05 \\
17.30 \pm 0.06 \\
10.20 \pm 0.10 \\
42.50 \pm 0.15 \\
100.00 \pm 0.05 \\
100.00 \pm 0.01
\end{gathered}
$$

3 * Commercial detergent A: formulated with sodium silicates, amines and alcohols; Commercial 4 detergent $\mathrm{B}$ : formulated with phosphoric acid and paint strippers; Commercial detergent C: 5 formulated with ammonium hydroxide; Commercial detergent D formulated with set of 6 hydrogenated (aliphatic and naphthenic) alkaline solvents with high dielectric strength. 7 
Figure 1

Illustration of foam fractionation method. Air inlet and foam formation from $P$. aeruginosa ATCC 10145 cell-free broth (1); foam transport to receiving flask (2); foam coalescence and air outlet (3). 


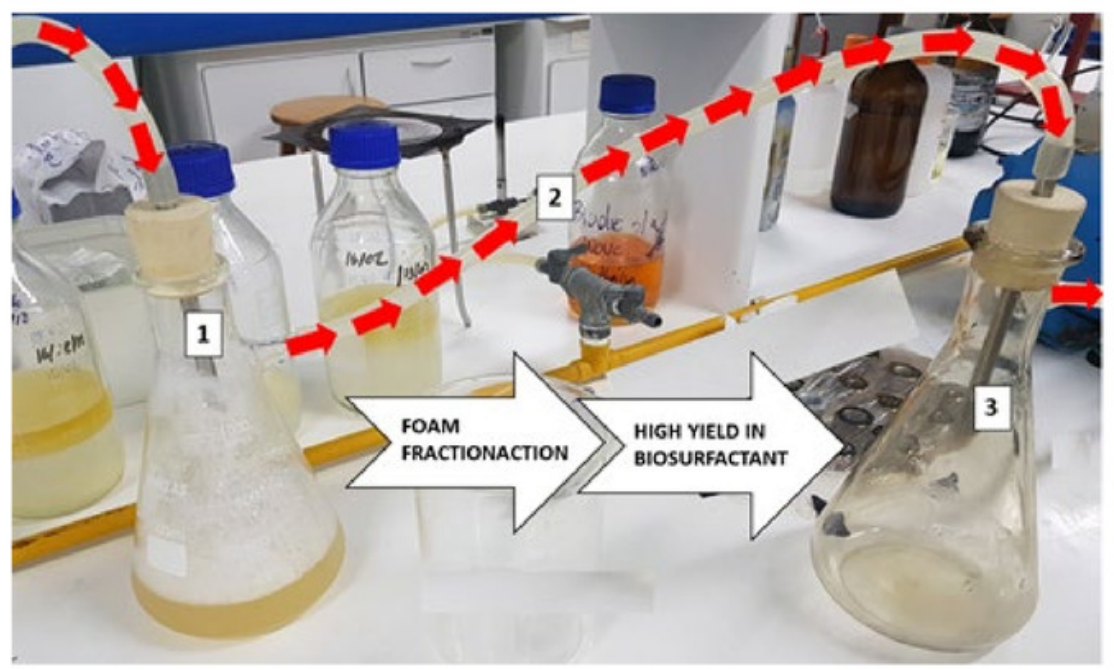


Figure 2

Surface tensions after culture of $P$. cepacia CCT6659 (60 h, $250 \mathrm{rpm})$ at 28 and $37^{\circ} \mathrm{C}$ (Soares da Silva et al., 2013) and at 28 and $37^{\circ} \mathrm{C}(96 \mathrm{~h}, 200 \mathrm{rpm})$ in glycerol and glucose (A) and in glucose (B).

Data presented are the average of triplicate experiments and error bars indicate standard deviation around the mean $(* * * 0.2-0.5 ; * * 0.6-1.4)$. 


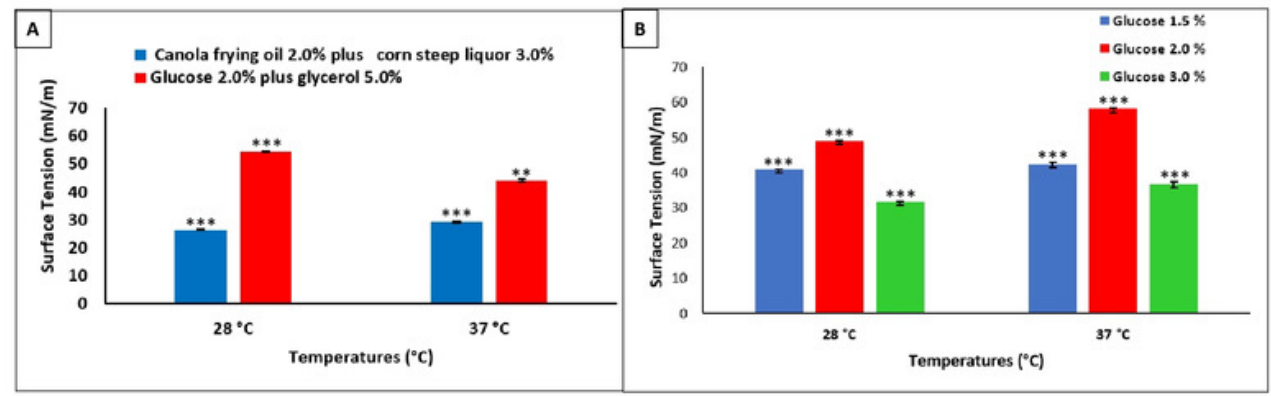


Figure 3

Surface tensions obtained after culture of $P$. aeruginosa UCP 0992. Fermentations performed for 96 hours at $200 \mathrm{rpm}$ at 28 and $37^{\circ} \mathrm{C}$ in media containing sucrose (A) and glucose (B).

Data presented are the average of triplicate experiments and error bars indicate standard deviation around the mean $(* * * 0.2-0.5)$. 


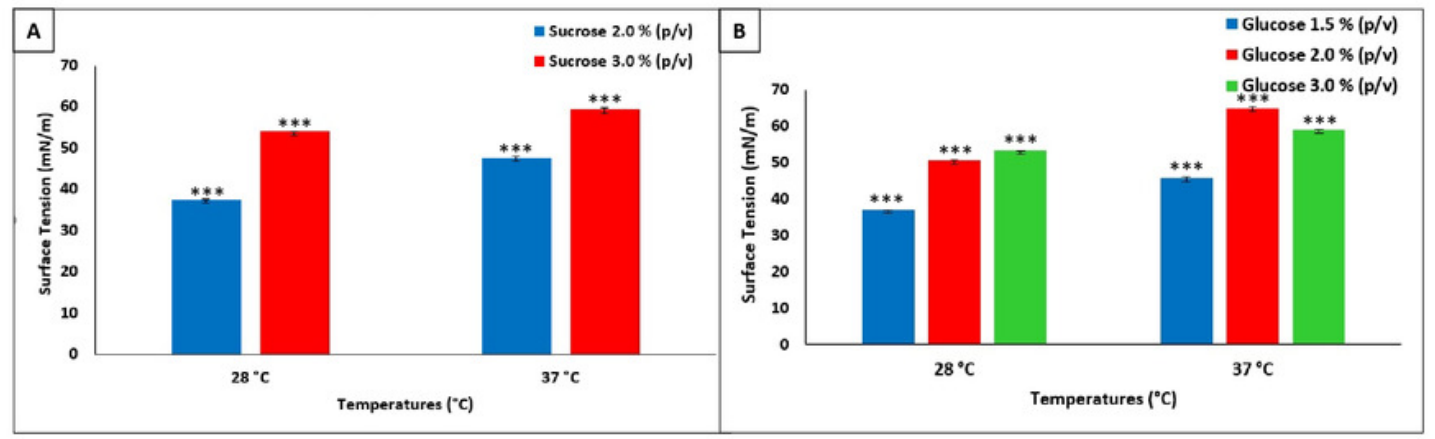


Figure 4

Surface tensions after culture of $P$. aeruginosa ATCC 10145 and $P$. aeruginosa ATCC 9027 in glycerol plus glucose, hexadecane plus glucose and molasses plus corn steep liquor at $28^{\circ} \mathrm{C}(\mathrm{A})$ and $35^{\circ} \mathrm{C}(\mathrm{B})$.

Data presented are the average of triplicate experiments and error bars indicate standard deviation around the mean $(* * * 0.2-0.5 ; * * 0.6-1.4)$. 


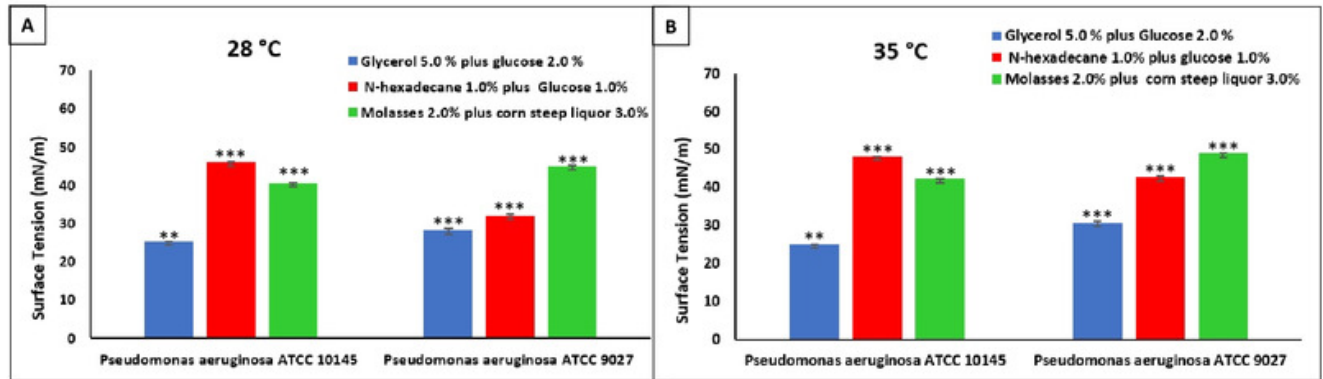


Figure 5

Emulsification capacity of biosurfactants from $P$. aeruginosa ATCC 10145 and $P$. aeruginosa ATCC 9027 in medium composed of $5.0 \%$ glycerol and $2.0 \%$ glucose for $96 \mathrm{~h}$ at $28^{\circ} \mathrm{C}$ with different oils.

Data presented are the average of triplicate experiments and error bars indicate standard deviation around the mean $(* * * 0.2-0.5 ; * * 0.6-1.4 ; * 1.5-2.0)$. 


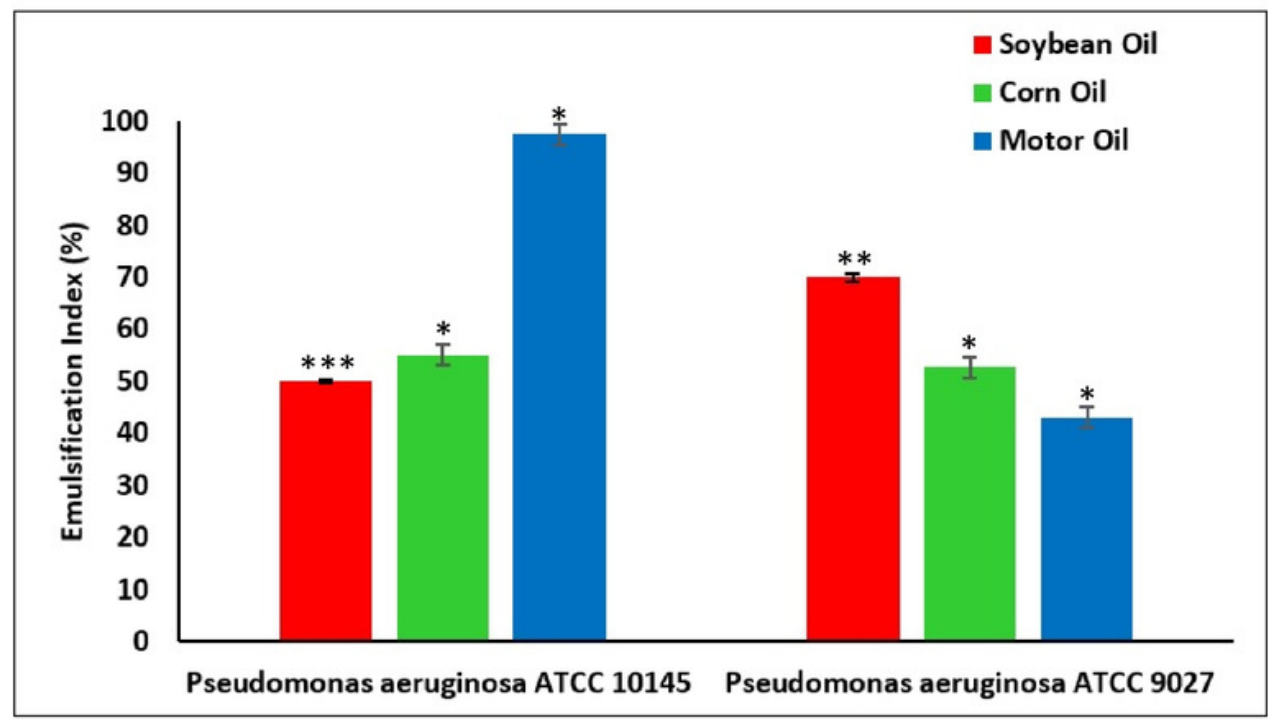


Figure 6

Dispersion of motor oil by biosurfactants from $P$. aeruginosa ATCC 10145 and $P$. aeruginosa ATCC 9027 cultivated in $5.0 \%$ glycerol and $2.0 \%$ glucose for $96 \mathrm{~h}$ at $28^{\circ} \mathrm{C}$.

Data presented are the average of triplicate experiments and error bars indicate standard deviation around the mean $\left({ }^{* * *} 0.2-0.5 ; * * 0.6-1.4\right)$. 


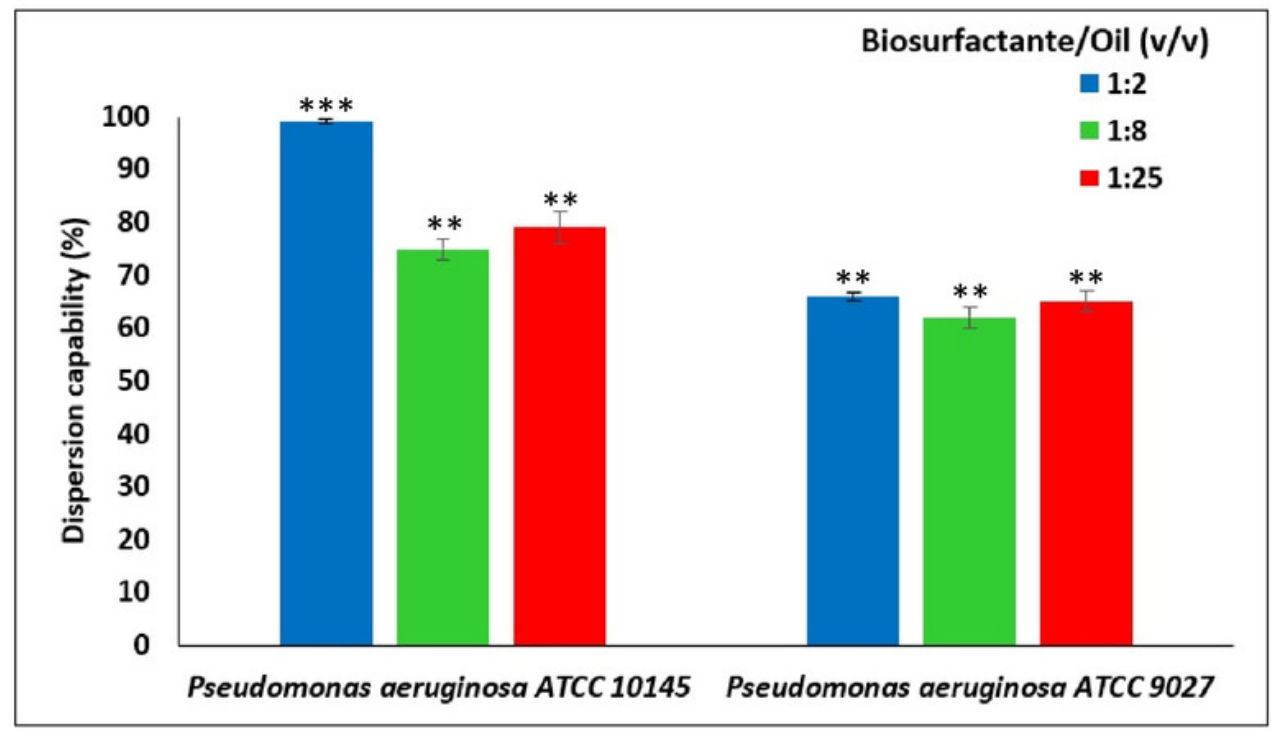


Figure 7

Critical micelle concentration plots of the biosurfactants produced from (A) $P$. aeruginosa ATCC 10145 and (B) P. aeruginosa ATCC 9027 cultivated in $5.0 \%$ glycerol and $2.0 \%$ glucose for $96 \mathrm{~h}$ at $28^{\circ} \mathrm{C}$. 


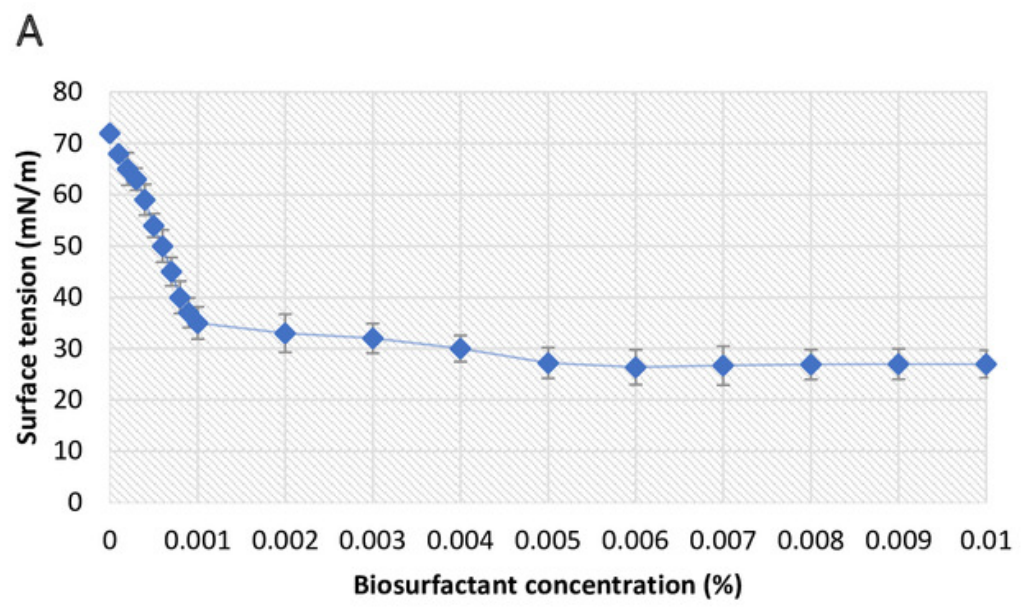

B

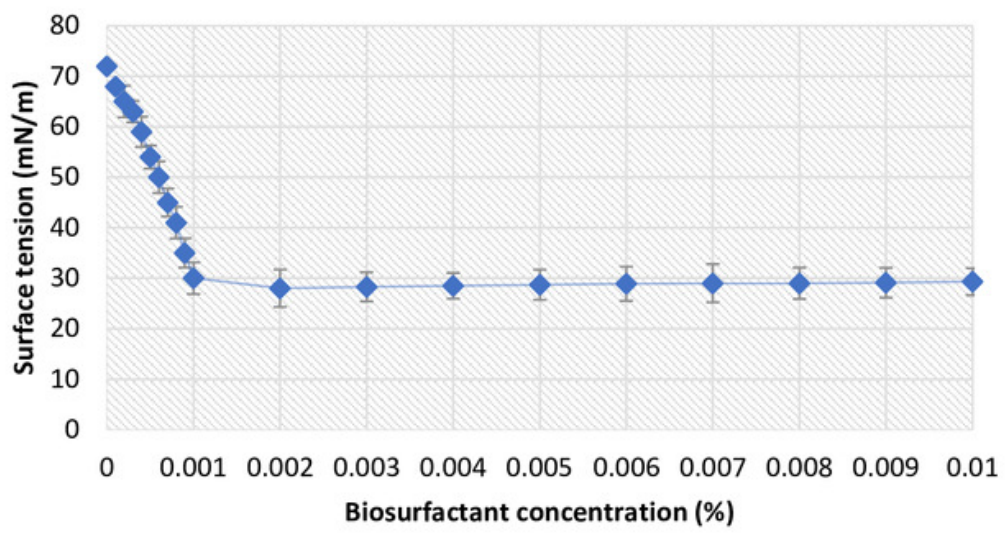


Figure 8

Foam formation promoted by biosurfactant from $P$. aeruginosa ATCC 10145 cultivated in $5.0 \%$ glycerol and $2.0 \%$ glucose for $96 \mathrm{~h}$ at $28^{\circ} \mathrm{C}$. Crude biosurfactant ( $\mathrm{A}$ and $\mathrm{B}$ ) and isolated biosurfactant (C). 


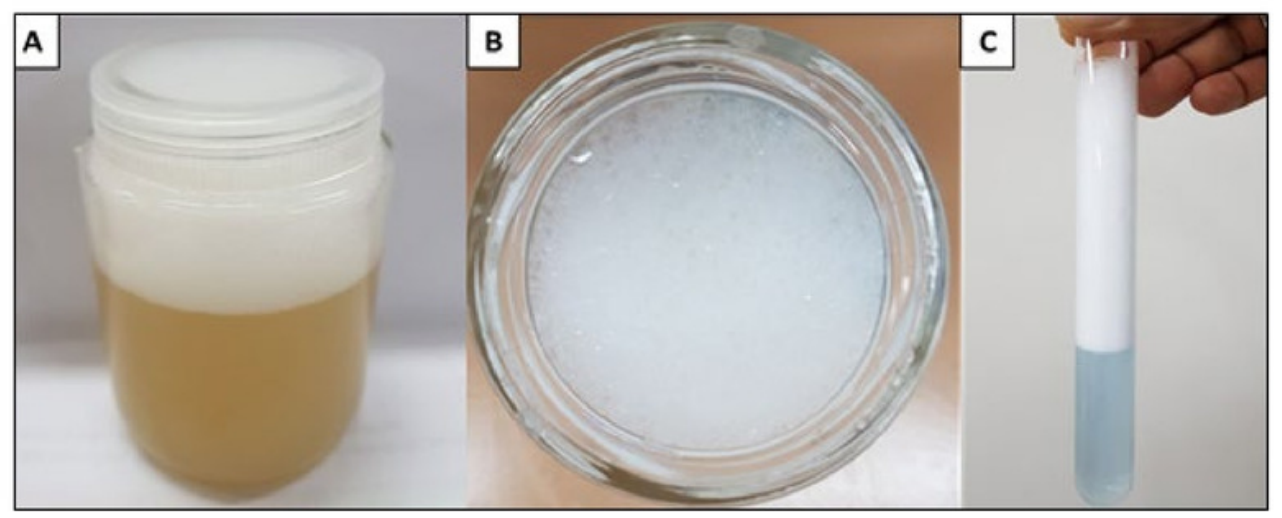




\section{Figure 9}

Removal of heavy oil (OCB1) from contaminated surface by industrial detergent formulated with the biosurfactant from $P$. aeruginosa ATCC 10145 cultivated in 5.0\% glycerol and $2.0 \%$ glucose.

(A) Heavy oil impregnated glass slide for detergent immersion. (B) Oil-impregnated slide immersed in detergent. (C) Immersion in distilled water for complete removal of destabilized oil from glass surface. (D) Complete oil removal. 


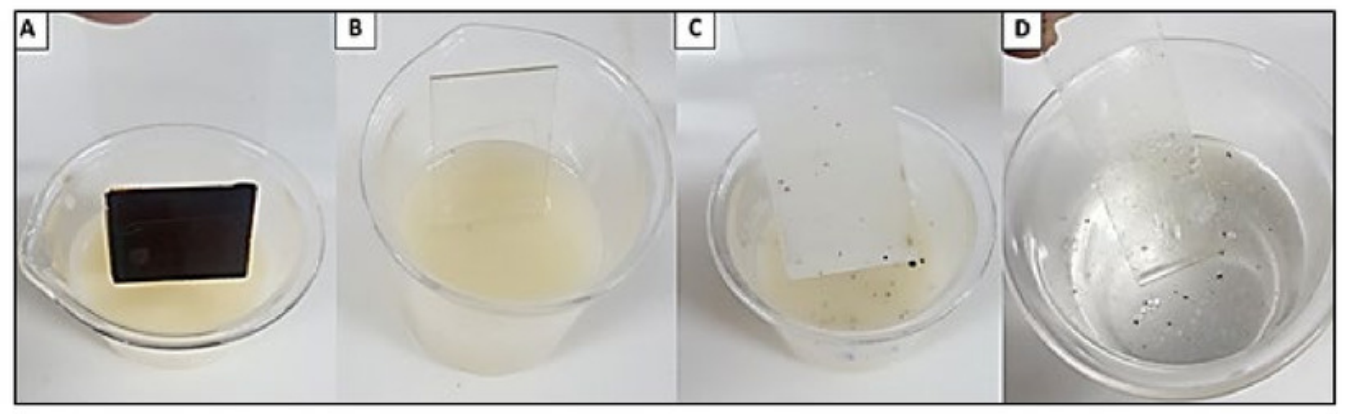




\section{Figure 10}

Removal of heavy oil (OCB1) from metallic and plastic surfaces by industrial detergent formulated with biosurfactant from $P$. aeruginosa ATCC 10145 cultivated in 5.0\% glycerol and $2.0 \%$ glucose.

I - Metallic surface. (A) Threaded nuts impregnated with heavy oil OCB1 for immersion in detergent threaded. (B) Nuts impregnated with oil immersed in detergent. (C) Immersion in distilled water for complete removal of destabilized oil from metal surface. (D) Complete oil removal. II - Plastic surface. (A) OCB1 oil-impregnated plastic storage container for detergent application. (B) Application of detergent to oil-impregnated surface. (C) Complete oil removal. 


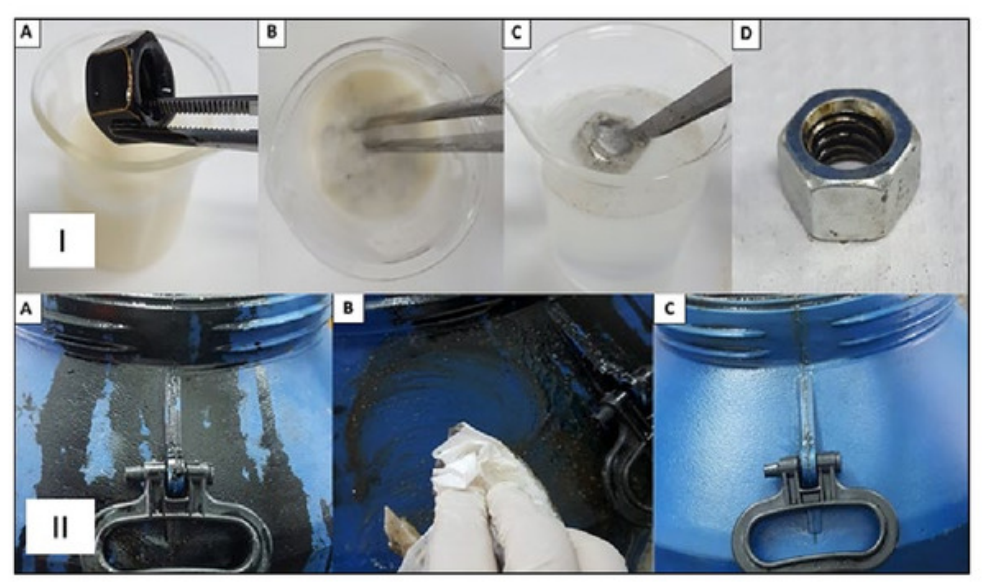

